\title{
METHODS OF IMPROVEMENT OF FORECASTING OF DEVELOPMENT OF MINERAL DEPOSITS' POWER SUPPLY
}

\author{
Alexander V. Putilov*, Alexander G. Vorobev, Dmitriy V. Timokhin, Marina \\ V. Bugaenko, Galina I. Popova \\ ${ }^{1}$ Faculty of Management and Economics of High Technologies, Moscow, Russia
}

Received 08.09.2014

Accepted 06.10.2014

\begin{abstract}
Mineral deposits (among which non-ferrous metals take a leading place) are situated on the territory of our planet rather unevenly, and often in out-of-the-way places. Nuclear power (particularly, transportable nuclear power plants) provides the new possibilities of power supply, which is very important for deposits' development. This article shares the economic aspects of forecasting in the field of power development (in particular, nuclear power on the basis of transportable nuclear power plants). Economic barriers of development of innovative nuclear technologies are considered on the example of transportable nuclear power plants. At the same time, there are given the ways of elimination of such barrier to development of this technology as methodical absence of investigation of a question of distribution of added cost between producers of innovative equipment and final product. Addition of new analytical tool ("business diagonal") is offered for a method of definition of economically efficient distribution of added cost (received as a result of introduction of innovative technologies) between participants of production and consumption of atomic energy within the "economic cross" model. There is offered the order of use of method of cash flows discounting at calculations between nuclear market participants.

Economic methods, offered in this article, may be used in forecasting of development of other energy technologies and introduction of prospective energy equipment.

Key words: transportable power unit, economic assessments, added cost, discount rate, innovative nuclear energy sources, nuclear energy, natural resource rent, minerals, evaluation, rough estimation.
\end{abstract}

\section{Introduction}

At the initial stage the programs of foresight-research have been basically devoted to futurological forecasts of science and technologies development, including perspective power technologies $[1,2]$. The forecast of the new markets for nuclear

*Corresponding autor: A. Putilov, AVPutilov@mephi.ru 
power stations of small and average capacity mostly depends on the technologies of their creation, including equipment transportation. Directly plant manufacturing and delivery to the place of operation of such type of the nuclear power station can be admitted as the most advances technology.

The economic feasibility of the financing of the "know-how" development and exploitation of transportable nuclear power plants (TrNPP) is defined by two factors:

- The additional revenue position created by the possibility of natural resources development where it was impossible before;

- A share of each of TrNPP manufacturers in use of extra received natural rent. Non-renewable (non-reproducible) and renewable (reproducible) power resources are distinguished among primary power resources. Organic kinds of the mineral fuel extracted from earth interiors (oil, natural gas, coal, combustible schist, others bituminous rocks, peat) are considered to be non-renewable power resources. To renewable (reproducible and practically inexhaustible) power resources one carry hydraulic power (rivers energy), and also so-called nonconventional (or alternative) energy sources: solar, wind, the energy of the internal heat of the Earth (including geothermal), thermal energy of oceans, the tidal energy. Nuclear or an atomic energy should be especially marked as non-renewable power resource as radioactive (mainly uranium) ores are its source. However in due course, with gradual replacement of the nuclear power stations working on thermal neutrons with the nuclear power stations using breeder reactors on fast neutrons, and in the future - thermonuclear energy, resources of nuclear power will become practically inexhaustible.

Russia plays an important role in the world mineral resources sector. Its share is: $28 \%$ natural gases; $26 \%$ diamonds; $14 \%$ iron ores; $13 \%$ colour and rare metals; $12 \%$ oils etc of the total amount of the minerals extracted in the world.

\section{Perspective power technologies and power resources life cycles}

The questions of economic indicators estimation at forecasting of the nuclear power industrial sector (NPIS) development on long prospect is a rather actual issue.

The estimation of perspective of this or that technology development is influenced by its market demand, including, on the one hand, size of additional added cost which this technology can create, and on the other hand - definition of the part of this added cost going to innovator.

This problem is aggravated by the fact that «innovator» is mostly not just one firm or a group of affiliated companies, but representatives of branches and sectors. At the same time one part of the enterprises is raw materials manufacturers (for example, extraction and enrichment of uranium, manufacture of innovative kinds of fuel), and another one manufactures means of production. Creation of TrNPP assumes the participation of several enterprises in the innovative project that is impossible without the creation of a certain model of the participation distributed in time, specific "road map" of a collective reinventor.

Recently in works of many authors the main principles of the power systems development economic estimations, including the description of power resources life cycles (search, extraction, preparation for use, power generating, liquidation or neutralization of biowaste), as well as of power units (designing, building, operation, a retirement from operation) are formulated. A bright example of this approach is socalled the «economic cross»: the joint representation of life cycles of power resources 
and power units, the crossing of which describes the decision of a technical problem (heat and electric power generation), and also defines power technology economic target achievement (the arrival of means for energy producing) [3]. The horizontal part of the «economic cross» characterizes the economy of a concrete power recourse life cycle, and the vertical one - of the power unit, using this power recourse. The point of the crossing of this «economic cross»'s sides characterizes commodity output formation at operation of power units: power generation (the electricity, heat supply services and so forth) and the corresponding economic result.

In the world practice there are requirements and criteria of the recognition of a project as an effective one (including nuclear engineering):

Absolute guarantee of the safety of the atomic power station functioning;

Recoupment of the investments into the development of nuclear engineering for the investor or their group;

Efficiency of the project (including the economic one) from the point of view of the society, i.e. excess of the society gain over corresponding expenses, maintenance of possibilities for the consecutive innovative development of the project, for example using innovative nuclear fuel for a nuclear power station.

The script «inflationary technological breakthrough» [4] assumes the presence of preconditions to global surplus of savings formation, the target investment of which can lead to a new technological breakthrough. It doesn't leave Russia any other way, except embedding in world industrial chains. If at the "warming up" of financial markets there will be no breakthrough, the world will face high inflation and the intensification of nonconventional kinds of hydrocarbonic fuel development because of expensive oil (another script - «power inflation»). At this point there are two variants of development for our country, each of which has its strengths and weaknesses. In the first case (the «clever raw» script) traditional actives will have to be recapitalized; in the second one («own pole») - it will be necessary to increase competitive advantages at the expense of state-private partnership development, theattraction of direct portfolio investments, the modernization of mass productions, the reforming of economic institutes.

\section{Economic aspects of forecasting of power objects life cycle}

The consumed energy used in the human community can be conditionally divided into household and industrial energy. The first one defines the quality of life, daily maintenance of the population with necessary services, including thesafety of living. Another kind of energy is industrial, or the energy of big capacities. Nowadays specific power consumption of Russian economy in comparison with industrially developed countries unfortunately remains rather high, and the industrial energy is extremely demanded. Taking into account the purchasing-power parity the given indicator twice exceeds a similar indicator in the USA; 2.3 times - as a whole on the world community and 3 times - in comparison with Japan and the developed countries of Europe.

For the manufacture of goods and services 1000 dollars cost in Russia $0.89 \mathrm{t}$ of conditional fuel (t c. f.) are spent, and in Norway and Sweden, having similar climatic conditions, just 0.36 and $0.26 \mathrm{t}$ c. f. accordingly. Forecasting the development of nuclear energetic as a part of power industrial sector it is important to consider perspective nuclear power resources (part of fuel power resources) and types of nuclear power sets, allowing to provide reproduction of these power resources (reactors on fast neutrons - 
RFN). One of the restrictions of modern nuclear engineering with an open nuclear fuel cycle (NFC) and reactors on thermal neutrons is the considerable and constantly accruing volumes of kept fulfilled nuclear fuel (FNF). Besides, these technologies do not allow using the energy contained in fuel nuclear materials to the full as more than 90 $\%$ of the extracted uranium remain in sailings of concentrating manufacture, and the efficiency of use of the fuel in reactors with the water heat-carrier (type WHC) is low. The complex timely decision of existing problems is possible by concentration of efforts and resources on the creation of nuclear power technologies of a new generation on the basis of RFN with closed NFC. It is no coincidence that there is a corresponding federal target program devoted to this direction of development.

In order to create and approach the market of new technologies, products and services for the traditional (power) markets State corporation "Rosatom" within the frame of the Commission at the President of the Russian Federation on modernization and technological development of Russian economy has initiated the project «The New technological platform: the closed nuclear fuel cycle and reactors on fast neutrons», being realized in the federal target program «Nuclear power technologies of a new generation for 2010-2015 and on prospect till 2020» (further FTP NPTNG) [5-15]. The higher level of nuclear and radiation safety should become the important effect of the project realisation.

The essence of estimations of possible economy of perspective power engineering development consists in excess of the gain over expenses at all stages of the life cycle taking into account the discounting and the time difference of expenses. In case of using TrNPP during the estimation it is also necessary to consider the added cost (the natural rent) which is provided by the use of TrNPP and without which this rent cannot be received. The scheme showed on pic. 1 [3], can be used in forecasting estimations for the development of both nuclear and alternative power resources:the slate gas, the slate oil, renewable power resources and so forth.

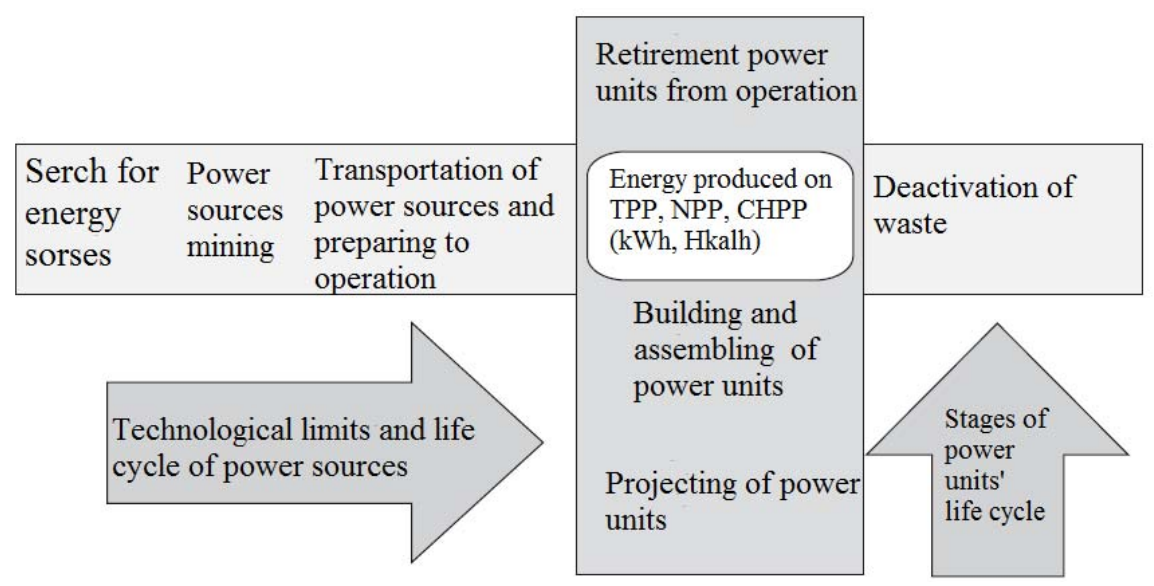

Fig.1. The essense of use the method of an "economic cross" in forecasting of power engineering development. 


\section{Construction principles of the "economic cross" for the formation of forecasts of TrNPP development.}

Any forecasts in energetic should consider the alternative development of power technologies - the future competitors in the power market (nuclear generation, generation on the organic fuel, renewable power). Therefore at economic estimations of such forecasts it is necessary to consider possible alternatives. On pic. 2 there are graphic details of a so-called «economic cross» in forecasting of transportable nuclear power plants development, at which along with power it is necessary to consider the use of natural resources in that region where the TrNPP is delivered.

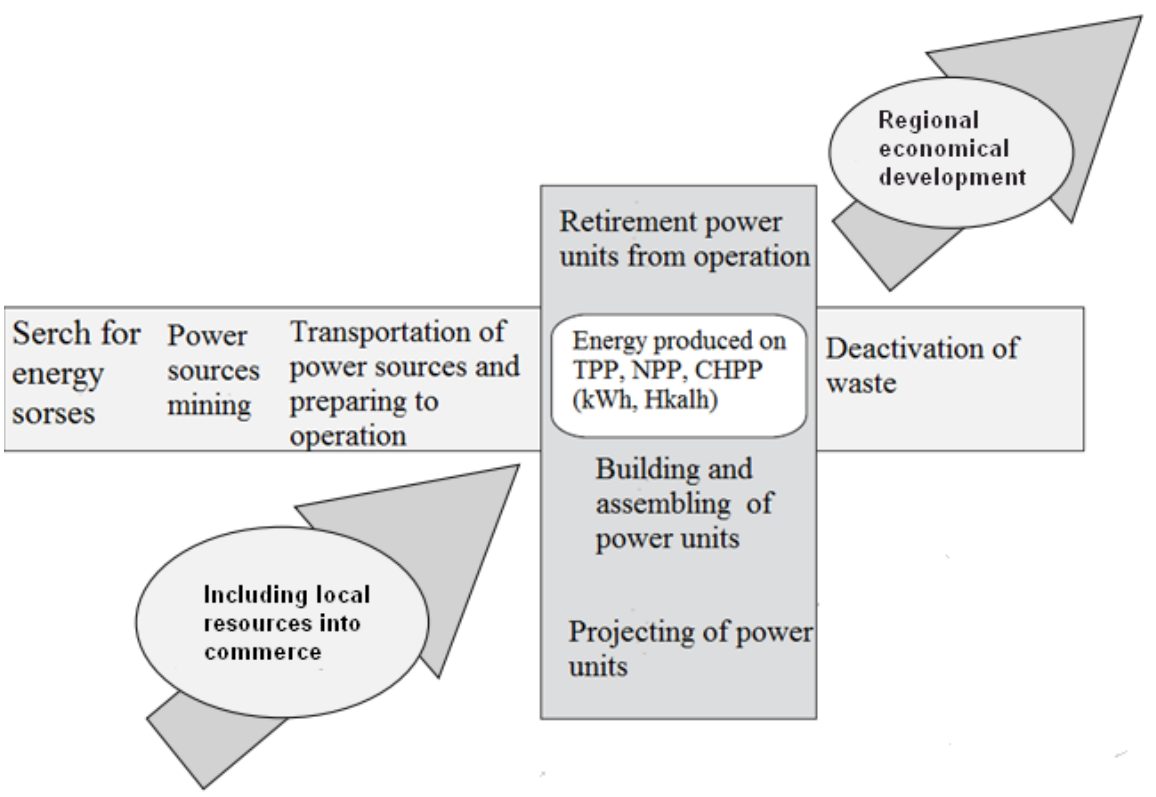

Fig.2. The principle of "business-diagonal" during the use of the method of "economic cross" for transportable NPP

In nuclear engineering an operating technological platform will co-exist with the extraction and enrichment of uranium and a new arising technological platform with chemical repartition FNF and short circuit NFC for a long time. For TrNPP a perspective variant can be the processing of FNF in industrial conditions with the replacement of nuclear power units for the maintenance of their efficiency in the same places after the set term of operation.

The main thing that distinguishes TrNPP from traditional nuclear power units, delivery in the ready form to the place of their operation and, therefore, inclusion in the economic circulation of those natural resources on the territory served by the TrNPP. The most advantageous is the sea transportation of TrNPP that is confirmed by the creation in Russia of floating nuclear power plant (FNPP) "Akademik Lomonosov", the operation of nuclear ice breakers, other examples of the use of nuclear power units.

As an estimation of the TrNPP contribution to concrete region's natural resources development it is offered to use the total discounted added cost (DAC), received as a 
result of economic activities of operating enterprises or objects during the development of new fields in the region for a defined forecast period [6].

The gain of DAC can be calculated as follows:

$$
\begin{gathered}
\Delta \mathrm{DAC}=\mathrm{DAC}^{\mathrm{l}}-\mathrm{DAC}^{\mathrm{b}}=\mathrm{i}=\ln \left(\mathrm{FOPi}^{1+N P i 1+\mathrm{Ai} 1+\mathrm{Ti} \mathrm{l})}-\mathrm{i}=\right. \\
=\ln \left(\mathrm{FOPi}^{\mathrm{b}+\mathrm{NPib}+\mathrm{Aib}+\mathrm{Ti} b)},\right.
\end{gathered}
$$

Where DAC ${ }^{\mathrm{l}}, \mathrm{DAC}^{\mathrm{b}}$ - accordingly the total added cost of the operating and predicted mountain enterprises in the last year of the forecast period and the operating enterprises in the base year, million rbl.; $\mathrm{FOPi}^{1}, \mathrm{NPi}^{1}, \mathrm{Ai}^{1}, \mathrm{Ti}^{1}$ and $\mathrm{FOPi}^{\mathrm{b}}, \mathrm{NPi}^{\mathrm{b}}, \mathrm{Ai}^{\mathrm{b}}, \mathrm{Ti}$ ${ }^{b}$ - accordingly fund of a payment with allocations, net profit, depreciation charges and a total sum of the taxes withheld from realised production, salary, profit and property of ith mountain enterprise in the last year of the forecast period and in the compared base year, million rbl.

\section{Economic comparison of various variants of atomic engineering fuel provision}

The perspective road map of nuclear power technologies development up to the middle of the century is made and fixed by a number of strategic and economic documents, including federal target programs. At the same time it is also impossible to ignore initiative projects and suggestions appearing during researches and development [7]. On pic. 3 a block of reactors on thermal neutrons (thermal reactors - TR) has a section of low power energy units among which there are all variants of the created TrNPP (FNPP and so forth)

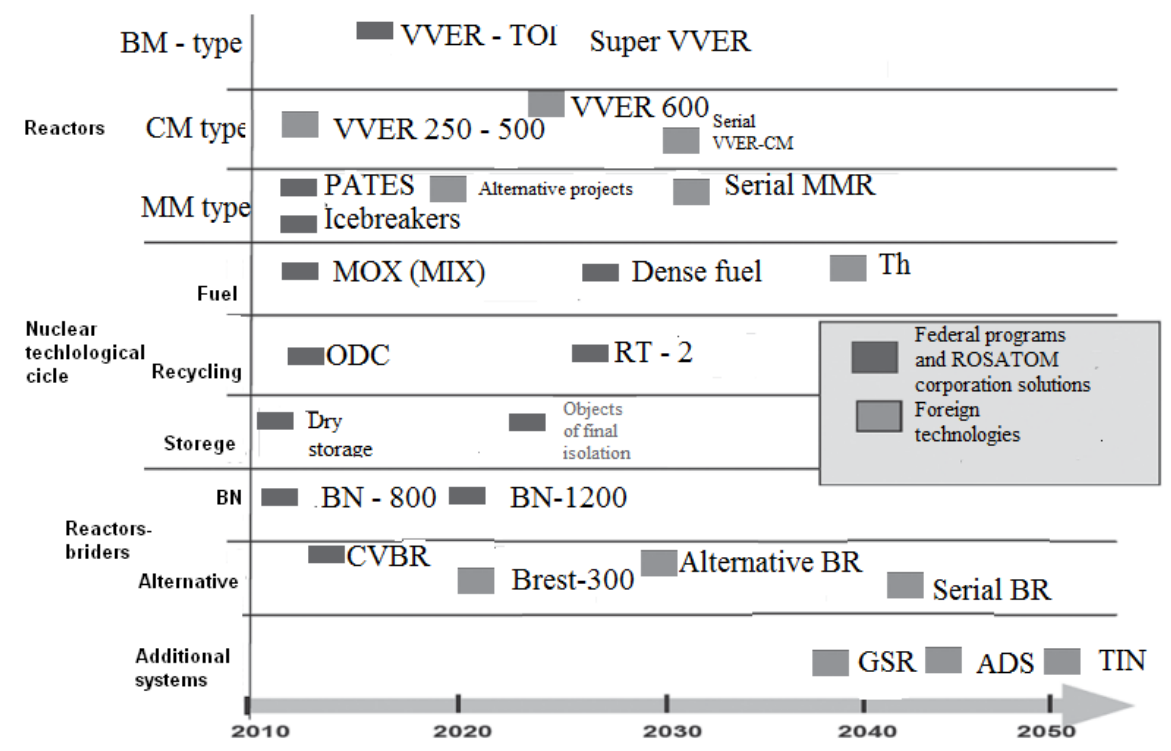

Fig. 3. Roadmap of nuclear technology development in Russia 
The influence of the nuclear power resources type on the efficiency of innovative atomic engineering development is obvious. Therefore a rather actual problem is the finding of the economic model allowing at least approximately to estimate available projects and with discounting expenses corresponding taking into account. For the objectivity of economic estimations at forecasting of the nuclear power complex (NPC) development, it is important also to consider the innovative development of the foreign companies-analogues, such as EDF, Fortum or Vattenfall in particular [8]. The chosen foreign power companies are the analogues of State Atomic Energy Corporation "Rosatom" and are also state companies. They developed dramatically in the second half of the last century in the conditions of superfluous financing and have a considerable experience if the operating nuclear power stations management.

The analysis of the expenses structure and the declared priorities of researches and development of the listed companies allows to reveal two basic tendencies of their technological development.

The first one is the increase of economic and technological efficiency of nuclear engineering development. In expectation of the growth of demand for nuclear engineering the leading companies were carrying out investments into preparation of a new technological platform for competition in the international markets, including new types of nuclear power units and nuclear fuel.

The second one is the necessity of power technologies diversification, the creation of nuclear power stations of small and average capacity, the development of technologies in the area of distributed generation that is obvious from the analysis of foreign experience.

Following modern tendencies of world power systems changing toward the distributed generation and ecological compatibility increase, the foreign power companies-analogues accomplish investments into the development of various alternative energy sources and searching for technological decisions for the distributed electric power industry.

\section{Tendencies of economic approaches to the development of new technologies in nuclear engineering}

The analysis of structure of expenses and the priorities of researches and of foreign nuclear companies development has allowed to educe the following tendencies.

1. The strengthening by the foreign companies of the positions in nuclear business at the expense of working out high technologies for the reactors of the third and fourth generation and the geographical expansion in the world nuclear market using the data of power complexes, and also the realization of vertical integration by the formation of strategic partnership.

2. The realization by the nuclear companies of seed investments into contiguous areas. Similar to the power ones the nuclear companies inject investments into technologies in the area of alternative power industry development (France), and also in other contiguous with atomic engineering areas in which their key technological competence can be used, for example, in the manufacture of hydrogen fuel, nuclear medicine, ecological technologies. The international alliances' entry into new nonpower markets will promote the decrease of their dependence on the cyclicality of the power branch, the increase in economic return of basic researches and the developed 
technologies and, thus, the further realisation of more scale researches for greater working out of new innovate technologies.

Preliminary expecting economic estimations of perspective power systems can be accomplished on the basis of the analysis of trends (pic. 4).

Capital expenditures per type of fuel

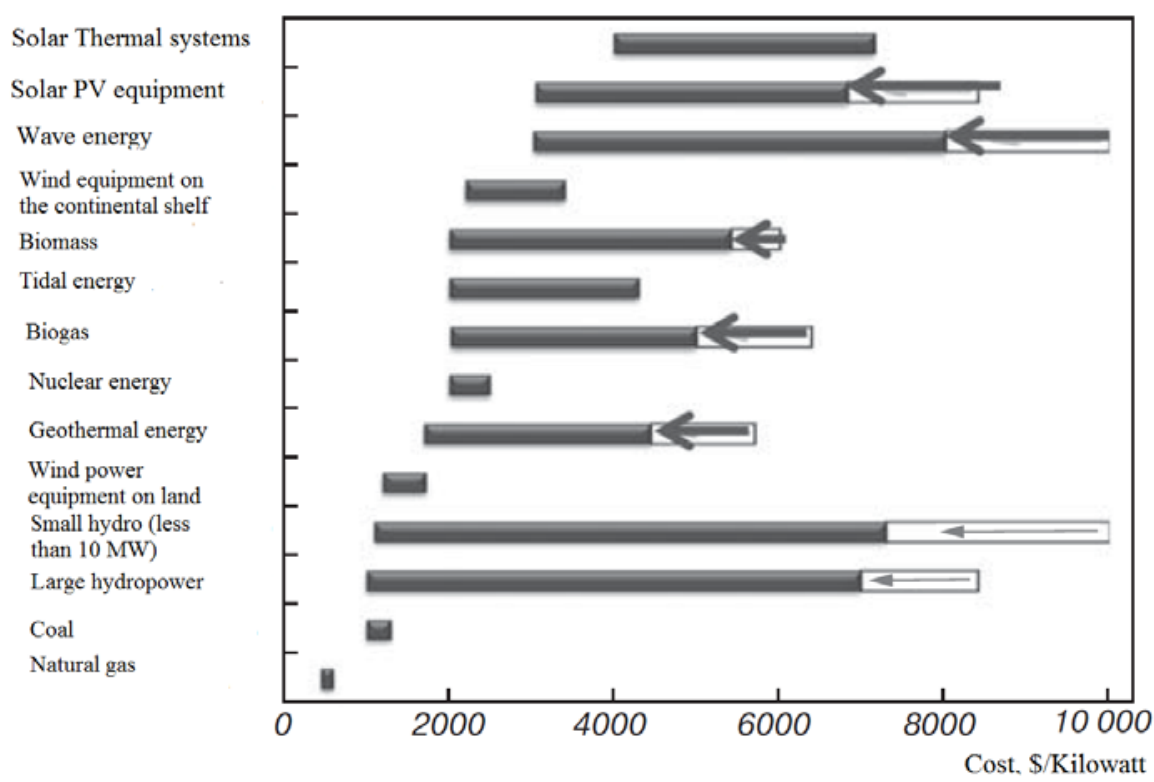

Fig. 4. Comparative estimates of capital costs per $1 \mathrm{~kW}$ unit at the use of various energy sources (the arrows show the trend cost reduction in recent years)

However such estimations are rather approximate, and they should be used while comparing alternative power technologies of essentially different nature.

\section{Forecasting the stages of innovative process of territories development on the TrNPP basis}

According to the concept of the «economic cross» the creation and the operation of TrNPP assumes the involving of new resources in the process of electric power manufacture and their effective operation (the horizontal axis of the «"economic cross»), as well as innovation of a hardware support of the electric power manufacture (the vertical axis of an "economic cross»).

Accept there is some income D received by an intermediate (or final) buyer of TrNPP from his activity as which can be considered as the gain of DAC or gross regional product that is provided by the inclusion in the economic circulation of natural resources using TrNPP. How to provide such gain of income $\Delta \mathrm{D}$ for it to appear not less than some value $\Delta \mathrm{S}$ which makes an increase in the value of power source in comparison with traditional ones? The participants of the introduction in a production cycle of a new kind of power source, for example TrNPP, are both the intermediate seller and the intermediate buyer of an the innovation, but at different stages. The price 
at which the consumer buys TrNPP, increases on some value $\Delta \mathrm{C}$ including as actual increase of seller's costs $\Delta \mathrm{S}$, as well as the economic interest of the manufacturer of TrNPP. It is necessary to define, how $\Delta \mathrm{S}, \Delta \mathrm{C}$ and $\Delta \mathrm{D}$ are corresponded, i.e. what proportions the shares of the income of various innovative process participants should have. According to operating practice 1.3 can be considered to be the base-line value of $\Delta \mathrm{C}$ (see, for example, the recommendations for assessment of intellectual property objects of 23.04.2011 and the comments to them). Therefore, cumulative economic benefit for all participants using innovative nuclear technologies, is rated as

$$
\Delta \Pi=\Delta \mathrm{D}-\Delta \mathrm{S}
$$

The intermediate seller (the founder of the TrNPP) receiving his share in this chain participates

$$
\Delta \Pi_{1}=\Delta \mathrm{C}-\Delta \mathrm{S}
$$

And the intermediate buyer (maintaining TrNPP) whose share will make

$$
\Delta \Pi_{2}=\Delta \Pi-\Delta \Pi_{1}
$$

For economically "fair" distribution of total result between the participants it is possible to consider as base the parity between the expenses for preparation to manufacture a new kind of power source $\left(\mathrm{S}_{1}\right)$ and expenses for the very production with the use of TrNPP $\left(\mathrm{S}_{2}\right)$. In case when the expenses $\mathrm{S}_{2}$ after the introduction of the innovative process differ from the expenses before the introduction, the difference, starting with logic of the primacy of the participant motivation, should be attributed to $\mathrm{S}_{1}$ as the entrepreneurial risks are initially taken by their owner.

Thus, the value $\Delta \Pi$ is fairly distributed between separate participants (the founder of TrNPP and the user of this power source for natural resources development) in the following ratio:

$$
\begin{aligned}
& \Delta \Pi_{1}=\mathrm{S}_{1} / \mathrm{S}, \\
& \Delta \Pi_{2}=\mathrm{S}_{2} / \mathrm{S} .
\end{aligned}
$$

The offered approach allows to include the income of use a new power sourse (for example, TrNPP) in its economic characteristics, for example, in the form of the natural rent, that is possible to estimate in more details on the examples of concrete projects.

\section{The conclusion}

Forecasting the innovative development of nuclear engineering along with technical and technological aspects it is also necessary to consider objectively the economic component. For this purpose in the article the method of the decision of a problem of each innovative process participant motivation on the basis of "fair", i.e. economically viable, distribution of a part of the final product added cost, appeared because of the introduction of the innovative decision (TrNPP) in the production, between all the innovative process participants. This approach to the decision of the conflict of interests problem in perspective power production can be successfully used at forecasting for preliminary estimations and screening of a priori irrational decisions. 


\section{References}

[1] Yakovets Yu., Kuzyk B., Kushlin V. Prognozirovanie, strategicheskoe planirovanie i natsionalnoe programmirovanie (Forecasting, strategic planning and national programming). Moscow : Ekonomika, 2011.

[2] Daheim C., Uerz G. Corporate foresight in Europe: from trend based logics to open foresight. Technology Analysis \& Strategic Management. 2008. Vol. 20, No. 3. pp. 321-336.

[3] Putilov A. V., Vorobev A. G. Ekonomika v promyshlennosti - Economics in industry. 2013. No. 1.pp. 35-40.

[4] Abramova E. A., Apokin A. Yu., Belousov D. R., Mikhaylenko K. V., Penukhina E. A., Frolov A. S. Forsayt - Foresight-Russia. 2013. Vol. 7, No. 2. pp. 6-25.

[5] Putilov A. V., Vorobev A. G., Strikhanov M. N. Innovatsionnaya deyatelnost v atomnoy otrasli. Kniga 1. Osnovnye printsipy innovatsionnoy politiki (Innovative activities in nuclear branch. Book 1. The basic principles of innovation policy). Moscow : "Ore and Metals" Publishing House, 2010. 184 p.

[6] Lukyanchikov N. N. Prirodnaya renta i okhrana okruzhayushchey sredy (Natural rent and environmental protection). Moscow, 2004. 129 p.

[7] Sidorenko V. A. Rosenergoatom - "Rosenergoatom" journal. 2012. No. 6. pp. 918.

[8] Putilov A. A., Vorobev A. G., Putilov A. V., Goldman E. L. Ekonomika v promyshlennosti - Economics in industry. 2009. No. 2. pp. 2-13.

[9] Putilov A. A., Vorobev A. G., Putilov A. V., Goldman E. L. Ekonomika v promyshlennosti - Economics in industry. 2009. No. 3. pp. 13-21.

[10] Ilina N. A., Putilov A. V. Innovatsii - Innovations. 2012. No. 9. pp. 10-15. 